\title{
Mechanical, antibacterial and bond strength properties of nano-titanium-enriched glass ionomer cement
}

\author{
Rene GARCIA-CONTRERAS ${ }^{1}$, Rogelio Jose SCOUGALL-VILCHIS², Rosalía CONTRERAS-BULNES ${ }^{3}$, Hiroshi \\ SAKAGAMI $^{4}$, Raul Alberto MORALES-LUCKIE ${ }^{5}$, Hiroshi NAKAJIMA ${ }^{6}$
}

\author{
1- Laboratorio de Investigación Interdisciplinaria, Área de Biomateriales Dentales, Escuela Nacional de Estudios Superiores (ENES) Unidad León, Universidad \\ Nacional Autónoma de México (UNAM), Guanajuato, México. \\ 2- Chairman of Dental Research Center "Dr. Keisaburo Miyata”. Department of Orthodontics, Autonomous University State of Mexico (UAEM), Toluca, México. \\ 3- Department of Pediatric Dentistry, Dental and Advanced Studies Research Center (CIEAO), Faculty of Dentistry, Autonomous University State of Mexico \\ (UAEM), Toluca, México. \\ 4- Division of Pharmacology, Meikai University School of Dentistry, Sakado, Saitama, Japan. \\ 5- Sustainable Chemistry Research Center, Autonomous University State of Mexico (UAEM), Toluca, México. \\ 6- Division of Dental Biomaterials Science, Meikai University School of Dentistry, Sakado, Saitama, Japan.
}

Corresponding address: Rogelio J. Scougall-Vilchis - Chairman of Dental Research Center "Dr. Keisaburo Miyata". Department of Orthodontics, Dental and Advanced Studies Research Center (CIEAO) - Faculty of Dentistry, Autonomous University State of Mexico (UAEM) - Tollocan-Jesus Carranza - Colonia Universidad - Toluca - México - e-mail:rscougallv@uaemex.mx/rogelio.scougall@orthodonticsrs.com/rogelio_scougall@hotmail.com

Submitted: December 11, 2014 - Modification: April 15, 2015 - Accepted: May 27, 2015

\section{ABSTRACT}

\begin{abstract}
Thesero he use of nanoparticles (NPs) has become a significant area of research in Dentistry. Objective: The aim of this study was to investigate the physical, antibacterial activity and bond strength properties of conventional base, core build and restorative of glass ionomer cement (GIC) compared to GIC supplemented with titanium dioxide $\left(\mathrm{TiO}_{2}\right)$ nanopowder at 3\% and 5\% (w/w). Material and Methods: Vickers microhardness was estimated with diamond indenter. Compressive and flexural strengths were analyzed in a universal testing machine. Specimens were bonded to enamel and dentine, and tested for shear bond strength in a universal testing machine. Specimens were incubated with S. mutans suspension for evaluating antibacterial activity. Surface analysis of restorative conventional and modified GIC was performed with SEM and EDS. The analyses were carried out with Kolmogorov-Smirnov, ANOVA (post-hoc), Tukey test, Kruskal-Wallis, and Mann Whitney. Results: Conventional GIC and GIC modified with $\mathrm{TiO}_{2}$ nanopowder for the base/ liner cement and core build showed no differences for mechanical, antibacterial, and shear bond properties $(p>0.05)$. In contrast, the supplementation of $\mathrm{TiO}_{2} \mathrm{NPs}$ to restorative GIC significantly improved Vickers microhardness $(p<0.05)$, flexural and compressive strength $(p<0.05)$, and antibacterial activity $(p<0.001)$, without interfering with adhesion to enamel and dentin. Conclusion: GIC supplemented with $\mathrm{TiO}_{2} \mathrm{NPS}$ (FX-II) is a promising material for restoration because of its potential antibacterial activity and durable restoration to withstand the mastication force.
\end{abstract}

Keywords: Glass ionomer cements. $\mathrm{TiO}_{2}$ nanoparticles. Antibacterial activity. Physical properties. Shear bond strength.

\section{INTRODUCTION}

Glass ionomer cement (GIC) possesses certain properties of adhesive ${ }^{23}$, biocompatibility ${ }^{2}$, and fluoride releasing ${ }^{3}$, which have led to worldwide use as luting, base, liners and restorative materials. However, the major disadvantages are fracture toughness, low wear-resistance and in the past high dissolution in a water sorption ${ }^{23}$ resulting in a base, build or restoration failure leading to a growth of bacterial proliferation consequential in secondary caries or teeth fracture. The incorporation of hydroxyethyl-methacrylate (HEMA) or bisphenolglycidyl-methacrylate (Bis-GMA) enhanced 
properties for compressive strength, hardness, higher modulus of elasticity, higher resistance to solubility and resistance to bacterial adhesion ${ }^{14}$. Significant perfections have been developed since the invention of GIC, numerous filler components have been added including; silver-amalgam particles $^{1}$, spherical silica ${ }^{26}$, zirconia ${ }^{12}$, glass fiber $^{13}$, hydroxyapatite ${ }^{20}$, bioactive glass particles as pre-reacted glass ionomer particles (PRG), giomer restorative material ${ }^{15}$. The incorporation of the filler particles above to GIC has significantly modified the mechanical properties of cements; however, fillers can interfere with metabolic activities for bacterial adhesion and inhibit the antibacterial activity of $\mathrm{GIC}^{4}$. In contrast, the use of nanoparticles (NPs) has become a significant area of research in Dentistry, the main use have been focused in increasing the mechanical properties and antibacterial effect; altering the hydrogen bonding, respiratory process, DNA unwinding, cell wall synthesis and division by making "pits" in the wall and increasing the permeability resulting in a bacterial death ${ }^{11}$. Recently, incorporation of hydroxyapatite and fluoroapatite nanobioceramics into conventional GIC improved their mechanical properties and bond strength to dentine ${ }^{22}$. Titanium dioxide $\left(\mathrm{TiO}_{2}\right)$ as an inorganic additive has many promising properties as it is chemically stable, biocompatible and antibacterial ${ }^{28}$. NPs have been proposed as reinforcing fillers to dental resin composites and epoxy ${ }^{30}$. It has recently been reported that (i) the incorporation of $\mathrm{TiO}_{2} \mathrm{NPs}$ to GIC at $3 \%$ and $5 \%(\mathrm{w} / \mathrm{w})$ significantly enhanced the fracture toughness, compressive strength, flexural strength and hardness, and (ii) GIC supplemented with $\mathrm{TiO}_{2}$ NPs showed antibacterial activity against Streptococcus mutans without interference with fluoride release; nevertheless, (iii) the incorporation of $7 \%$ of $\mathrm{TiO}_{2}$ NPs compromised the mechanical properties and adhesion ${ }^{6}$. We recently reported that, for $\mathrm{TiO}_{2}$ nanoparticles in culture with human gingival fibroblast (HGF) ${ }^{9}$ and oral squamous cell carcinoma cells $(\mathrm{HSC}-2)^{7}$, some particles were incorporated into the cells, exclusively in the vacuoles and showed no cytotoxic nor hormetic growth stimulation at lower concentrations. However, $\mathrm{TiO}_{2}$ NPs exert pro-inflammatory action by Interleukin-1 $\beta$ (IL-1 $\beta$ ) and stimulated the secretion of prostaglandin $\mathrm{E}_{2}\left(\mathrm{PGE}_{2}\right)$, Cyclooxygenase (COX) 1 and 2, and induced drastic metabolic changes ${ }^{10}$ to the culture medium by HGF cells and $\mathrm{TiO}_{2} \mathrm{NPs}$ also induced $\mathrm{PGE}_{2}$ production, in synergy with IL-1 $\beta$, the enhanced production of $\mathrm{PGE}_{2}$ was not simply due to LPS contamination ${ }^{9}$. Also, the incorporation of $\mathrm{TiO}_{2}$ NPs to GIC exhibits acceptable to moderate biocompatibility in culture with human oral normal cells [pulp cells (HPC), gingival fibroblast (HGF), periodontal ligament fibroblast (HPLF)] and human cancer cells [oral squamous cell carcinoma (OSCC): HSC-2, HSC-3, HSC-4 and gingival carcinoma $(\mathrm{Ca9}-22)]^{8}$.

Based in the previously reports, we expected that the supplementation of $\mathrm{TiO}_{2}$ NPs to GIC enhance its mechanical and antibacterial properties, the objective of this research is to investigate the physical properties (microhardness, flexural and compressive strength), the antibacterial activity and the bond strength of base, core build up and restorative GIC compared to GIC modified with $\mathrm{TiO}_{2}$ nanopowder at 3\% and 5\% (w/w).

\section{MATERIAL AND METHODS}

Powder of each GIC was blended with $\mathrm{TiO}_{2}$ nanopowder, anatase phase, particle size $<25 \mathrm{~nm}$ (Sigma-Aldrich, St. Louis, MO, USA) at 3\% and 5\% $(\mathrm{w} / \mathrm{w})$. GIC powder and $\mathrm{TiO}_{2}$ NPs were mixed in a vortex for one minute.

\section{Vickers microhardness test}

GIC cylinders $(9.5 \times 1 \mathrm{~mm})(\mathrm{n}=5)$ were made in a Teflon mold according to ADA specification 27 after being prepared following the manufacturer's instruction. The recommended powder/liquid (P/L) ratio of $2.6 / 1 \mathrm{~g}$ was mixed for cements. Cylinders were tested in ISO 9001:2008 certified diamond indenter (DongGuan Sinowon precision instruments, Nancheng, China) with $10 \mathrm{~N}$ and a dwell time of $10 \mathrm{~s}$ were employed for 10 indentations across the specimens of each group resulting in $\mathbf{5 0}$ indentations of each group. Since Vickers microhardness test is more sensitive to measurement errors than Knoop test and best for small rounded areas, we decided to use the method based on the ISO 9917-1:200716.

\section{Flexural and compressive strength}

Twenty cylinder specimens were prepared as mentioned above. Cylinders were subjected to three points bending in a universal testing machine (AGS-X, Shimadzu, Kyoto, Japan) at cross speed of $1 \mathrm{~mm} / \mathrm{min}(\mathrm{MPa})$. Flexural strength (MPa) was calculated using the following formula:

\section{$\mathrm{O}^{\prime}=3 \mathrm{Pl} / 2 \mathrm{bd} 2$}

where $O^{\prime}$ is the flexural strength, $P(N)$ is the load at fracture, I is the distance between the two supports $(\mathrm{mm}), b$ is the width of the specimen $(\mathrm{mm})$, and $\mathrm{d}$ is the thickness $(\mathrm{mm})$. On the other hand, compressive strength of specimens was performed by the universal testing machine at cross speed of $1 \mathrm{~mm} / \mathrm{min}$ (MPa), and calculated using the following equation:

$$
\mathrm{CS}=2 \mathrm{P} / \mathrm{ndh}
$$

where CS is the compressive strength, $P(N)$ is the load at fracture, $d$ is the diameter of specimen $(\mathrm{mm})$, and $\mathrm{h}$ is the thickness $(\mathrm{mm})$. Flexural and compressive strength were determined according 
to ISO $9917-1: 2007^{16}$ and ISO $9917-2: 2010^{17}$.

\section{Shear bond strength to enamel and dentine}

A total of 180 freshly extracted anterior bovine teeth were stored in 0.1 thymol solution. Teeth were randomly divided into the nine groups ( $n=20 /$ group). Samples were fixed in acrylic resin (NicTone 62, MDC Dental, Guadalajara, Mexico) with a label bearing the number of each sample. A mounting jig was used to align each tooth's labial surface. Standardized GIC blocks $(4 \times 4 \times 1 \mathrm{~mm})$ were preformed in a metal mold following the manufacturer's instructions. Before adhering the block to the dental surfaces with fresh cement, the sample surfaces were finished with $\# 400$ waterproof abrasive paper (Fuji Star, Sankyo, Rikagaku, Okegawa, Japan). In the case of enamel bond strength, vestibular surface was sandblasted (Micro Cab, Danville, San Ramon, CA, USA) with $50 \mu \mathrm{m}$ of aluminum dioxide (Danville, San Ramon, CA, USA) for one minute. Then, teeth underwent ultrasonic cleaning for one minute (Quantrex, Kearny, NJ, USA). Consequently, for testing the bond strength in dentin, the vestibular surfaces of the teeth were reduced approximately $1.5 \mathrm{~mm}$ with a high speed diamond bur (SS White Burs Inc, Lakewood, NJ, USA). At that point, dentinal surface was sandblasted and underwent ultrasonic cleaning as mentioned above. Immediately after direct bonding the GIC block with appropriate powder/ liquid proportion, samples were stored in water at $37^{\circ} \mathrm{C}$ during $24 \mathrm{~h}$. Shear bond strength to enamel and dentine was carried out in a universal testing machine at cross speed of $1 \mathrm{~mm} / \mathrm{min}$ (MPa). Force was applied at the interface of the GIC block and dental surface.

\section{Antibacterial activity}

Suspension of approximately $10^{5}$ Streptococcus mutans (S. mutans, ATCC 35668) was cultivated in brain heart infusion broth (Becton Dickinson, NJ, USA) for 18 hours. Bacteria solution was subcultivated in brain heart agar (Becton Dickinson, $\mathrm{NJ}$, USA). Immediately, blocks $(4 \times 4 \times 1 \mathrm{~mm})$ of the different conventional GIC and GIC modified with $\mathrm{TiO}_{2}$ NPs at $3 \%$ and $5 \%(\mathrm{w} / \mathrm{w})$ were set in direct contact over the agar containing the bacteria, after 24 hours of incubation at $37^{\circ} \mathrm{C}$, inhibit halos were measured with electronic digital caliper (NSK, Tochigi, Japan). Three blocks were set on each $100 \mathrm{~mm}$ plate containing the brain heart agar. Experiment was performed in triplicate to obtain reproducible data.

\section{SEM and EDS analysis}

Standardized GIC blocks $(4 \times 4 \times 1 \mathrm{~mm})$ of FX-II conventional, $\mathrm{FX}$-II $3 \%(\mathrm{w} / \mathrm{w}) \mathrm{TiO}_{2} \mathrm{NPs}$, and $\mathrm{FX}$-II $5 \%(\mathrm{w} / \mathrm{w}) \mathrm{TiO}_{2} \mathrm{NPs}$ were prepared in the metallic mold and covered with microslide glass. Samples were gently polished and finished with \#400, 1000 and 1500 waterproof abrasive paper (Fuji Star, Sankyo, Rikagaku, Okegawa, Japan). Subsequently, blocks were ultrasonically cleaned for five minutes in distilled water (Quantrex, Kearny, NJ, USA). All samples were adhered to aluminum stubs with conductive tape, coated with carbon and observed under SEM (PHILIPS XL-30, North Billerica, MA, USA) with secondary electrons at $\times 100, \times 500$, and $\times 3,000$ magnification by $20 \mathrm{kV}$. Energy-dispersive $X$-ray (EDS) analysis was developed at the same time of SEM micrographs. An area of approximately $20 \times 15 \mu \mathrm{m}$ was selected for analysis; relative values were obtained after $300 \mathrm{~s}$ of measurement.

\section{Statistical analysis}

Mean values and standard deviations were estimated. Vickers microhardness data were subjected to Kolmogorov-Smirnov normality test and ANOVA (post-hoc) Tukey test. In order to examine compressive and flexural strength, shear bond strength to enamel and dentine, and antibacterial activity data were analyzed with nonparametric Kruskal-Wallis and multiple comparisons of Mann-Whitney, the analyses were carried out with SPSS 18.0 (SPSS Inc., Chicago, III, USA). A value of 0.05 was considered statistically significant.

\section{RESULTS}

\section{Vickers microhardness}

Vickers microhardness data indicated normality and ANOVA test showed statistical differences $(p<.0001)$ between groups and post-hoc Tukey test results are enlisted in Table 1. It must be mentioned that, in all cases, the size of the indentations was larger than the filler particles, based on the size of fillers reported by the manufacturer. Data showed a significant increase in microhardness for the FX-II containing $3 \%$ and $5 \%(\mathrm{w} / \mathrm{w}) \mathrm{TiO}_{2}$ NPs compared to the conventional cement. Nevertheless, core shade and base cement did not present increased microhardness values; actually, the inclusion of nanopowder at both concentrations decreased the microhardness.

\section{Flexural and compressive strength}

The supplementation of $3 \%$ and $5 \%(\mathrm{w} / \mathrm{w})$ $\mathrm{TiO}_{2}$ NPs into $\mathrm{FX}$-II enhanced flexural strength $(p<0.05)$ and compressive strength $(p<0.0001)$, compared to the conventional cement. The minimal supplementation at $3 \%$ improved the properties of definitive restoration cement. Core shade build up cement improved only compressive strength when $5 \%(w / w)(p<0.05) \mathrm{TiO}_{2}$ NPs were incorporated, compared to the conventional GIC. Base cement did not $(p<0.05)$ show better properties with the 
Table 1- Mean (standard deviation) of Vickers microhardness (VHN) $(n=50)$, flexural $\left(\mathrm{O}^{\prime}\right)$ and compressive strength (Cs) and shear bond strength to enamel and dentin $(n=20)$ of $\mathrm{GIC}$ and $\mathrm{GIC}$ incorporated with $3 \%$ and $5 \%(w / w) \mathrm{TiO}_{2}$ nanopowder

\begin{tabular}{|c|c|c|c|c|c|c|}
\hline Cement & Group $^{\ominus}$ & VHN & $0^{\prime}$ & Cs & $\begin{array}{l}\text { Enamel bond } \\
\text { strength }\end{array}$ & $\begin{array}{c}\text { Dentin bond } \\
\text { strength }\end{array}$ \\
\hline \multirow{3}{*}{$\begin{array}{c}\text { Core shade } \\
\text { base cement } \\
\text { (Gray) }\end{array}$} & $\begin{array}{l}\text { Conventional } \\
\text { GIC }\end{array}$ & $56.9 \pm 9.6^{a}$ & $22.4 \pm 6.9^{a}$ & $7.1 \pm 3.9^{a}$ & $1.92 \pm 1.11^{a}$ & $1.90 \pm .92^{\mathrm{a}}$ \\
\hline & $\begin{array}{c}\text { GIC-3\% }(w / w) \\
\text { TiO2 }\end{array}$ & $47.1 \pm 6.5^{b}$ & $18.1 \pm 5.6^{a}$ & $8.8 \pm 3.0^{\mathrm{ab}}$ & $1.30 \pm .49^{a}$ & $1 \pm .40^{\mathrm{b}}$ \\
\hline & $\begin{array}{c}\text { GIC- } 5 \%(w / w) \\
\mathrm{TiO}_{2}\end{array}$ & $57.6 \pm 7.1^{\mathrm{a}}$ & $21.2 \pm 6.8^{a}$ & $9.6 \pm 2.5^{b}$ & $2.61 \pm 1.52^{\mathrm{a}}$ & $1.40 \pm .86^{\mathrm{b}}$ \\
\hline \multirow[t]{3}{*}{$\begin{array}{c}\text { Base cement } \\
\text { (Yellow) }\end{array}$} & $\begin{array}{l}\text { Conventional } \\
\text { GIC }\end{array}$ & $61.2 \pm 7.6^{a}$ & $20.8 \pm 5.6^{a}$ & $7 \pm 3.2^{\mathrm{a}}$ & $2.61 \pm 1.33^{a}$ & $.84 \pm .28^{a}$ \\
\hline & $\begin{array}{c}\text { GIC-3\% (w/w) } \\
\mathrm{TiO}_{2}\end{array}$ & $54.1 \pm 5.5^{b}$ & $20.2 \pm 5.9^{a}$ & $7.5 \pm 3.1^{\mathrm{b}}$ & $1.78 \pm 1.08^{b}$ & $.82 \pm .20^{\mathrm{a}}$ \\
\hline & $\begin{array}{c}\text { GIC- } 5 \%(w / w) \\
\mathrm{TiO}_{2}\end{array}$ & $58.4 \pm 5.2^{\mathrm{a}}$ & $18.3 \pm 4.3^{a}$ & $5.4 \pm 2.4^{c}$ & $1.78 \pm .91^{b}$ & $.87 \pm .21^{a}$ \\
\hline \multirow[t]{3}{*}{$\begin{array}{l}\text { FX-II Enhanced } \\
\text { restoration (A2) }\end{array}$} & $\begin{array}{l}\text { Conventional } \\
\text { GIC }\end{array}$ & $54.3 \pm 9.0^{\mathrm{a}}$ & $15.1 \pm 2.9^{a}$ & $5.6 \pm 2.3^{a}$ & $1.89 \pm 1.39^{a}$ & $1.32 \pm .74^{\mathrm{a}}$ \\
\hline & $\begin{array}{c}\text { GIC-3\% (w/w) } \\
\mathrm{TiO}_{2}\end{array}$ & $64.2 \pm 3.3^{b}$ & $20.2 \pm 4.1^{b}$ & $7.3 \pm 1.6^{b}$ & $1.96 \pm 1.47^{a}$ & $1.50 \pm .66^{\mathrm{a}}$ \\
\hline & $\begin{array}{c}\text { GIC- } 5 \%(w / w) \\
\mathrm{TiO}_{2}\end{array}$ & $63.8 \pm 4.1^{b}$ & $21.4 \pm 5.0^{c}$ & $8.6 \pm 1.5^{c}$ & $2.20 \pm 1.41^{a}$ & $.99 \pm .46^{a}$ \\
\hline
\end{tabular}

* GIC: Glass ionomer cement.

$\ominus$ TiO2: Titanium dioxide nanopowder.

Mean values for each cement group with the same superscript letter (column) are not significantly different ( $p>0.05)$, while mean values with different letters are significantly different $(p<0.05)$. Vickers microhardness was analyzed with ANOVA (post-hoc) Tukey test, while flexural and compressive strength, shear bond strength to enamel and dentin were analyzed by Mann Whitney test.

Table 2- Antibacterial activity of GIC and GIC incorporated with 3\% and 5\% (w/w) TiO nanopowder against Streptococcus mutans (ATCC 35668)

\begin{tabular}{|c|c|c|c|}
\hline Cement & Group $^{\ominus}$ & $\mathbf{n}$ & Inhibit halos (mm) \\
\hline \multirow{3}{*}{$\begin{array}{l}\text { Core shade base cement } \\
\text { (Gray) }\end{array}$} & Conventional GIC* & 18 & None \\
\hline & GIC-3\% (w/w) $\mathrm{TiO}_{2}$ & 18 & None \\
\hline & GIC-5\% (w/w) $\mathrm{TiO}_{2}$ & 18 & None \\
\hline \multirow[t]{3}{*}{ Base cement (Yellow) } & Conventional GIC & 18 & None \\
\hline & GIC-3\% (w/w) $\mathrm{TiO}_{2}$ & 18 & None \\
\hline & GIC-5\% (w/w) $\mathrm{TiO}_{2}$ & 18 & None \\
\hline \multirow{3}{*}{$\begin{array}{l}\text { FX-II Enhanced restoration } \\
\qquad(\mathrm{A} 2)\end{array}$} & Conventional GIC & 18 & $0.92 \pm 0.22^{\mathrm{a}}$ \\
\hline & GIC-3\% (w/w) $\mathrm{TiO}_{2}$ & 18 & $2.11 \pm 0.82^{b}$ \\
\hline & GIC-5\% (w/w) $\mathrm{TiO}_{2}$ & 18 & $1.53 \pm 0.79^{b}$ \\
\hline
\end{tabular}

* GIC: Glass ionomer cement.

$\ominus \mathrm{TiO}_{2}$ : Titanium dioxide nanopowder.

Mean values for each cement group with the same superscript letter (column) are not significantly different ( $p>0.05)$, while mean values with different letters are significantly different $(p<0.001)$ (Mann-Whitney test). 
addition of $\mathrm{TiO}_{2} \mathrm{NPs}$ compared to conventional GIC. The results are summarized in Table 1.

\section{Shear bond strength}

Data for shear bond strength ( $\mathrm{MPa}$ ) to enamel and dentine showed no statistical differences between the conventional GIC and that modified with $\mathrm{TiO}_{2}$ NPs (neither at 3\% nor at 5\%). There was a slight but insignificant increase in the shear bond strength to enamel in the case of the core shade with $5 \%(\mathrm{w} / \mathrm{w}) \mathrm{TiO}_{2} \mathrm{NPs}$, and $\mathrm{FX}-\mathrm{II}$ with $3 \%$ and $5 \%(\mathrm{w} / \mathrm{w}) \mathrm{TiO}_{2}$ NPs (Table 1 ).

\section{Antibacterial activity}

Bacterial growth activity (Table 2 ) was reduced on direct contact to FX-II conventional, FX-II 3\% and $5 \%(w / w) \mathrm{TiO}_{2}$ NPs. Inhibit halos values $(n=18)$ obtained corresponded to $0.92 \pm .22 \mathrm{~mm}, 2.11 \pm 0.82$ $\mathrm{mm}$, and $1.53 \pm 0.79 \mathrm{~mm}$, respectively. When the antibacterial activity of FX-II $3 \%$ and $5 \%(\mathrm{w} / \mathrm{w})$ $\mathrm{TiO}_{2}$ NPs was compared with conventional FX-II, significant differences were observed $(p<0.001)$ in both groups, and no difference was observed between FX-II $3 \%$ and $5 \%(\mathrm{w} / \mathrm{w}) \mathrm{TiO}_{2}$ NPs. The minimum supplementation of $3 \%$ or $5 \%(w / w)$
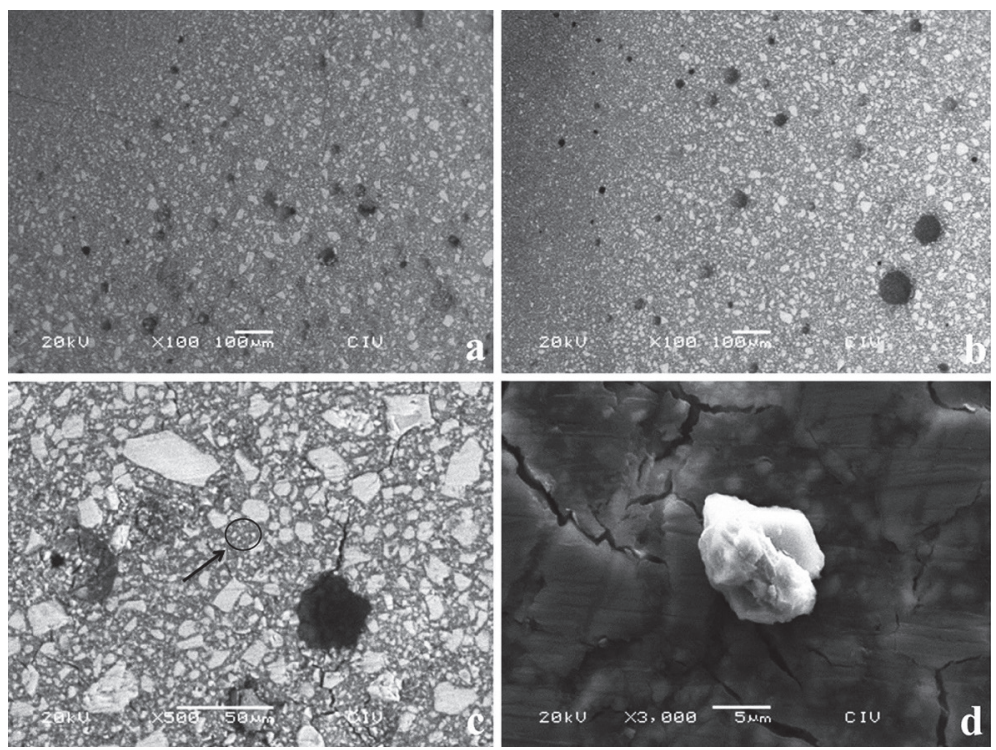

Figure 1- Blocks (4x4x1 mm) of (a) conventional FX-II, (b) FX-II 3\% (w/w) $\mathrm{TiO}_{2}$, and (c) $\mathrm{FX}-\mathrm{II} 5 \%$ (w/w) $\mathrm{TiO}_{2}$. Samples were gently polished and finished with \#400,\#1,000, and \#1,500 waterproof abrasive paper and ultrasonically cleaned. Topographically, there are no differences between specimens. Nevertheless, hybrid particles are observed, microparticles (1c, black circle and arrow) are uniformly lay between (matrix) macroparticles, and such particles seem to be grouped of $\mathrm{TiO}_{2}$ nanoparticles due to their angular and semispherical shape confirmed by the $1 \mathrm{~d}$ micrograph and EDS of this area, the zone exhibits higher concentration of titanium $(a \%=0.36 \%)$

Table 3- Energy-dispersive X-ray (EDS) analysis of conventional FX-II, FX-II with 3\% and 5\% (w/w) $\mathrm{TiO}_{2}$ nanopowder. Values represent atomic percentage $(\mathrm{a} \%)$

\begin{tabular}{cccc}
\hline Element & FX-II & FX-II-3\% (w/w) $\mathbf{T i O}_{2}$ & FX-II-5\% (w/w) $\mathbf{T i O}_{2}$ \\
\hline $\mathrm{C}$ & 78.1 & 59.6 & 60.3 \\
$\mathrm{O}$ & 11.2 & 30.56 & 30.63 \\
$\mathrm{~F}$ & 2.4 & 5.72 & 5.7 \\
$\mathrm{Al}$ & 3.3 & 1.68 & 1.33 \\
$\mathrm{Si}$ & 2.93 & 1.34 & 1.08 \\
$\mathrm{P}$ & 0.85 & 0.37 & 0.28 \\
$\mathrm{~S}$ & 0.006 & 0.001 & 0 \\
$\mathrm{Ti}$ & 0 & 0.11 & 0.17 \\
$\mathrm{Sr}$ & 1.16 & 0.57 & 0.44 \\
$\mathrm{Total}$ & $100 \%$ & $100 \%$ & $100 \%$ \\
\hline
\end{tabular}

FX-II: Enhanced restorative cement

$\mathrm{TiO}_{2}$ : Titanium dioxide nanopowder 
$\mathrm{TiO}_{2}$ NPs to GIC showed higher antibacterial activity against $S$. mutans than conventional FXII. Nevertheless, core shade and base cement conventional GIC with or without modification with $\mathrm{TiO}_{2}$ nanopowder showed no antibacterial properties in any specimens.

\section{SEM and EDS analysis}

Representative SEM micrographs are shown in Figure 1. Topographically, there are no apparent differences in the finish surfaces for FX-II, FX-II $3 \%$ and $5 \%(\mathrm{w} / \mathrm{w}) \mathrm{TiO}_{2} \mathrm{NPs}$. In Figure $1 \mathrm{C}$, hybrid particles are observed, microparticles uniformly lay between (matrix) macroparticles, and such particles seem to be grouped of $\mathrm{TiO}_{2} \mathrm{NPs}$ due to their angular and semispherical shape confirmed by the 1D micrograph. The composition of conventional GIC FX-II, FX-II 3\% and 5\% (w/w) $\mathrm{TiO}_{2}$ NPs are shown in Table 3. Based on EDS data, all materials showed dominant portions of carbon and oxygen. Titanium was detected in FX-II containing $3 \%$ and $5 \%(\mathrm{w} / \mathrm{w}) \mathrm{TiO}_{2} \mathrm{NPs}$, while the concentration of oxygen increased and strontium decreased, by incorporating the $\mathrm{TiO}_{2} \mathrm{NPs}$.

\section{DISCUSSION}

\section{Flexural and compressive strength}

Compressive and flexural tests are used in Dentistry for laboratory simulation of the stress that may result from forces applied clinically to a restorative, base/liner or core build material ${ }^{24}$. Most mastication forces are compressive in nature, but exact critical value is unknown ${ }^{28}$. Therefore, it is important to investigate whether compressive force contributes to fracture failure during mastication process. The minimum value necessary to resist the masticatory forces in the posterior teeth would be $125 \mathrm{MPa}$, while $100 \mathrm{MPa}$ for primary dentition ${ }^{29}$. Flexural forces are generated under clinical situations, and the dental materials need to withstand the repeated flexing, bending, and twisting forces. Microhardness test is a parameter frequently used to evaluate the material surfaces resistance to plastic deformation by penetration ${ }^{28}$. The powder/liquid ratio of GIC has an influence on the mechanical properties and bond strength ${ }^{31}$.

Improvement in flexural strength of the GIC FX-II was significantly higher at concentrations of $3 \%$ and $5 \%(\mathrm{w} / \mathrm{w}) \mathrm{TiO}_{2}$ NPs than conventional. Therefore, Ketac-Molar (3M ESPE, Seefeld, Germany) and Fuji IX (GC Corporation, Tokyo, Japan) have showed higher values of flexural strength than the cements in this study when performed specimens of $25 \times 2 \times 2 \mathrm{~mm}$. The reported flexural strength values of the cements above represent 33.3, 34.5 $\mathrm{MPa}$, respectively ${ }^{19}$. Supplementation of $3 \%$ and $5 \%(\mathrm{w} / \mathrm{w}) \mathrm{TiO}_{2} \mathrm{NPs}$ to $\mathrm{FX}$-II have results similar to those reported by Elsaka, et al. ${ }^{6}$ (2011) when restorative GIC (Kavitan Plus, SpofaDental, Czech Republic) was modified with $\mathrm{TiO}_{2}$ NPs.

On the other hand, the test procedures for compressive strength are not complicated. Although the compression specimen has a convenient cylindrical geometry, perfection of the ends (which is essential to produce uniform contact between the specimen and the testing device) is difficult to achieve. Compressive strengths for GIC FX-II containing 3\% and 5\% (w/w) $\mathrm{TiO}_{2}$ NPs were higher than that of conventional GIC. Compressive strengths of different conventional GIC such as Ketac Molar (3M ESPE), Fuji IX (GC), and Ketac-fil plus (3M ESPE) (146.28 to 152.41 $\mathrm{MPa}$ ) were higher than that of GIC studied here with or without supplementation of $\mathrm{TiO}_{2} \mathrm{NPs}$; the difference in values can be explained by the size of specimens ( $4 \mathrm{~mm}$ diameter and $6 \mathrm{~mm}$ high) ${ }^{19}$. Flexural and compressive strength improvement of FX-II containing $3 \%$ and $5 \%(\mathrm{w} / \mathrm{w}) \mathrm{TiO}_{2} \mathrm{NPs}$ can be attributed to the small sizes of the $\mathrm{TiO}_{2}$ particles supplemented into the glass powder and the presence of the NPs can occupy the empty spaces between the larger GIC glass particles and act as additional bonding sites for the polyacrylic polymer; this means that the base cement did not incorporate particles because of the small size particles and greater surface of $\mathrm{TiO}_{2}$ NPs compared to those of the glass.

\section{Vickers microhardness}

The GIC FX-II enhanced restoration containing $3 \%$ and $5 \%(\mathrm{w} / \mathrm{w}) \mathrm{TiO}_{2}$ NPs exhibit significantly higher Vickers microhardness compared to conventional GIC, while GIC with $5 \%$ (w/w) $\mathrm{TiO}_{2}$ NPs for base and core build showed no statistical differences in relation to conventional cement. The 3\% (w/w) $\mathrm{TiO}_{2}$ NPs rather decreased the Vickers microhardness; the supplementation of $\mathrm{TiO}_{2}$ NPs to FX-II powder possibly is related to the fewer glass particles on the surface of GIC, which result in greater amount of acid to react with the NPs. Different studies have focused on determining the hardness of conventional and modified GIC. Thus, conventional GIC as Ketac-fil (3M, ESPE), Fuji IX (GC), and Ionofil Molar (VOCO, Cuxhaven, Germany) have values of 90, 69.7, and 57.4 VHN, respectively ${ }^{18}$. Conventional FX-II enhanced restoration showed 54.3 VHN, lower values than the other GICs. On the other hand, the supplementation of $3 \%$ and $5 \%(\mathrm{w} / \mathrm{w}) \mathrm{TiO}_{2} \mathrm{NPs}$ to conventional FX-II showed higher values of 64.2 and 63.8 VHN, respectively. Meanwhile, microhardness values of metal reinforced cements like Fuji IX GP (GC) (from 54.44 to $61.77 \mathrm{VHN})^{21}$ showed lower microhardness than FX-II supplemented with $\mathrm{TiO}_{2}$ NPs; thus, Kavitan Plus restorative (SpofaDental) 
containing 3\%(w/w) $\mathrm{TiO}_{2}$ NPs represents 48.34 $\mathrm{VHN}^{6}$. Microhardness values of RMGIC such as Photac Fil (3M, ESPE), Vitremer (3M, St. Paul, MN, USA), and Fuji II LC (GC) showed values of 46.2, $51.4,69.2 \mathrm{VHN}^{21}$, respectively.

\section{Shear bond strength}

The chemical adhesion of GIC to enamel and dentin is achieved by reaction of phosphate ions in the dental tissue with carboxylate groups in the polyacrylic acid. Several factors can influence the bond strength, one of which is the type of dental substrate. Theoretical considerations and results of experiments show that enamel is much more susceptible to adhesion than dentin ${ }^{21}$. Enamel has a surface that is essentially homogeneous, dense, and mainly composed of hydroxyapatite, which possesses high surface energy. Dentin has a heterogeneous surface, containing dental tubules that contain odonto-plastic processes, consists of approximately $30 \%$ volume organic matter, and consequently has low surface energy ${ }^{19}$. The enamel bond strength of different GIC modified with 3\% and $5 \%(\mathrm{w} / \mathrm{w}) \mathrm{TiO}_{2} \mathrm{NPs}$ studied here showed similar values in relation to conventional cements except for Core shade containing 5\% (w/w) $\mathrm{TiO}_{2}$ NPs, which showed significantly higher values when bonding to enamel surface. Data reported here have similar or lower values of enamel shear bond strength than different studies carried out with conventional GIC such as Ketac-fil plus (3M ESPE), Ketac-Molar (3M ESPE), and Fuji IX (GC). These cements have reported values as follows: 4.9, 5.31, and $5 \mathrm{MPa}$ when debonding $3 \mathrm{~mm}$ in diameter of GIC adhered to enamel surface ${ }^{5,25}$. These low values were observed due to the sensitivity of GIC to moisture during setting. In our study, the comparison of scores recorded among the conventional GIC and GIC supplemented with $3 \%$ and $5 \%(w / w) \mathrm{TiO}_{2}$ NPs demonstrated that there is no difference between groups of cements, except for the core shade cement, which conventionally has higher adherence to dentinal surface than GIC modified with $\mathrm{TiO}_{2}$ NPs. Results can be explained by the incorporation of $\mathrm{TiO}_{2}$ NPs to powder of GIC, which does not interfere with the shear bond strength to dentin. In addition, some studies recorded shear bond strength values of 2.05, 308, and 3.79 MPa, respectively, for GIC Ketac-fil plus (3M ESPE), Ketac-Molar (3M ESPE), and Fuji IX (GC) $)^{5,25}$. Therefore, when both enamel and dentinal surfaces were sandblasted, the values of shear bond strength increase twice when debonding GIC specimens.

Consequently, GIC containing 3\% and 5\% (w/w) $\mathrm{TiO}_{2}$ NPs seem to be much more susceptible to dissolution in contact to water than conventional cement; it can be explained by the low ionic attraction between filler particles and $\mathrm{TiO}_{2} \mathrm{NPs}$ and the heterogeneous distribution of NPs into the filler particles when mixed at the recommended powder/ liquid ratio.

\section{Antibacterial activity}

On the other hand, the minimum supplementation of $3 \%$ or $5 \%(\mathrm{w} / \mathrm{w}) \mathrm{TiO}_{2}$ NPs to the $\mathrm{FX}-\mathrm{II}$ showed better antibacterial activity against $S$. mutans (ATCC 35668) than conventional FX-II. Similar antibacterial activity results are obtained for specimens of restorative GIC Kavitan Plus (SpofaDental) added with 3\%, 5\%, and 7\% (w/w) $\mathrm{TiO}_{2}$ nanopowder on direct contact to $S$. mutans (ATCC 27351) reported by Elsaka, et al. ${ }^{6}$ (2011). The base cement and core shade cement showed no antibacterial activity, possibly explained by the agglomeration of $\mathrm{TiO}_{2}$ NPs forming a conjugated particle that was not perfectly incorporated between the filler particles and matrixes of GIC as well as that particle attraction was positioned near the center of the cement without reactive surfaces in direct contact to bacteria, leading to ineffective bacterial growth inhibition. The antibacterial mechanism suggested that $\mathrm{TiO}_{2}$ NPs to produced reactive oxygen species (ROS), specifically, hydroxyl free radicals and peroxide, as previously reported ${ }^{27}$.

\section{SEM and EDS analysis}

Due to the unique properties detected in the FXII supplemented with $\mathrm{TiO}_{2} \mathrm{NPs}$ at $3 \%$ and $5 \%(\mathrm{w} / \mathrm{w})$, SEM observation and EDS analysis were performed to identify the topographical aspect and chemical interaction and composition of supplemented GIC; however, it is necessary to investigate the chemical interaction between $\mathrm{TiO}_{2}$ NPs and GIC composition by specific analyses, such as transmission electron microscopy (TEM) and sophisticated spectroscopies. Findings of EDS analysis showed as follows: between higher $\mathrm{TiO}_{2}$ amounts, lesser carbon composition and higher quantity of oxygen. On the other hand, the fluor composition when $\mathrm{TiO}_{2} \mathrm{NPs}$ is added to conventional FX-II GIC powder at 3\% and $5 \%$ increases, probably, due to the suitable interaction of glass particles and NPs showed better antibacterial effect ${ }^{28}$.

Among the limitations of study, further indepth antibacterial activity tests are necessary to be performed in future research to obtain reliable results using not only $S$. mutans but also aerobic, anaerobic and facultative bacterial. Further research is necessary to understand the fluor releasing from the GIC modified with $\mathrm{TiO}_{2}$ nanopowder.

\section{CONCLUSIONS}

GIC supplemented with $\mathrm{TiO}_{2}$ NPs is a promising dental material to be used as enhanced restoration due to its potential antibacterial properties and use 
in high-tension restoration considering the force of mastication.

\section{REFERENCES}

1- Bala O, Arisu HD, Yikilgan I, Arslan S, Gullu A. Evaluation of surface roughness and hardness of different glass ionomer cements. Eur J Dent. 2012;6:79-86.

2- Brentegani LG, Bombonato KF, Carvalho TL. Histological evaluation of the biocompatibility of a glass-ionomer cement in rat alveolus. Biomaterials. 1997;18:137-40.

3- Coffey JP, Robertello FJ, Lynde TA, King P. Fluoride release of glass ionomer-based luting cements in vitro. J Prosthet Dent. 1999;82:172-6.

4- Dhull KS, Nandlal B. Comparative evaluation of fluoride release from PGR-composites and compomer on application of topical fluoride: an in vitro study. J Indian Soc Pedod Prevent Dent. 2009;27:27-32.

5- El-Askary FS, Nassif MS, Fawzy AS. Shear bond strength of glass-ionomer adhesive to dentin: effect to smear layer thickness and different dentin conditioners. J Adhes Dent. 2008;10:471-9. 6- Elsaka SE, Hamouda IM, Swain MV. Titanium dioxide nanoparticles addition to a conventional glass-ionomer restorative: influence on physical and bacterial properties. J Dent. 2011;39:589-98.

7- Garcia-Contreras R, Scougall-Vilchis RJ, Contreras-Bulnes R, Ando $Y$, Kanda $Y$, Hibino $Y$, et al. Effect of $\mathrm{TiO}^{2}$ nanoparticles on cytotoxic action of chemotherapeutic drugs against a human oral squamous cell carcinoma cell line. In Vivo. 2014;28:209-15.

8- Garcia-Contreras R, Scougall-Vilchis RJ, Contreras-Bulnes $\mathrm{R}$, Kanda $\mathrm{Y}$, Nakajima $\mathrm{H}$, Sakagami $\mathrm{H}$. Effect of $\mathrm{TiO}^{2}$ nano glass ionomer cements against normal and cancer oral cells. In Vivo. 2014;28:895-907.

9- Garcia-Contreras R, Scougall-Vilchis RJ, Contreras-Bulnes R, Kanda $\mathrm{Y}$, Nakajima $\mathrm{H}$, Sakagami $\mathrm{H}$. Induction of prostaglandin E2 production by $\mathrm{TiO}^{2}$ nanoparticles in human gingival fibroblast. In Vivo. 2014;28:217-22.

10- Garcia-Contreras R, Susigmoto M, Umemura N, Kaneko M, Hatakeyama $Y$, Soga $T$, et al. Alteration of metabolomic profiles by titanium dioxide nanoparticles in human gingivitis model. Biomaterials. 2015;57:33-40

11- García-Contreras R, Argueta-Figueroa, Mejía-Rubalcava C, Jiménez Martínez R, Cuevas-Guajardo S, Sánchez-Reyna PA, et al. Perspectives for the use of silver nanoparticles in dental practice. Int Dent J. 2011;61:297-301.

12- Gu YW, Yap AU, Cheang P, Koh YL, Khor KA. Development of zirconia-glass ionomer cement composites. J Non Cryst Solids. 2005;351:508-14.

13- Hammouda IMN. Addition of glass fibers to conventional glass ionomer and composite resin restorative materials. Int J Mat Sci. 2007; 2:123-36.

14- Hibino $Y$, Kuramochi $K$, Harashima A, Honda M, Yamazaki A, Nagasawa $Y$, et al. Correlation between the strength of glass ionomer cements and their bond strength to bovine teeth. Dent Mater J. 2004;23:656-60.
15- Ikemura K, Tay FR, Endo T, Phashley DH. A review of chemicalapproach and ultramorphological studies in the development of fluoride-releasing dental adhesives comprising new pre-reacted glass ionomer (PGR) fillers. Dent Mater J. 2008;27:315-39.

16- International Organization for Standardization. ISO 9917:2007: Dentistry-water-based cements-part 1: powder/ liquid acid-base cements. Geneva: International Organization for Standardization; 2007.

17- International Organization for Standardization. ISO $9917-$ 2:2010: Water-based cements - Part 2: Resin-modified cements. Geneva: International Organization for Standardization; 2010. 18- Khouw-Liu VH, Anstice HM, Pearson GJ. An in vitro investigation of a poly (vinyl phosphonic acid) based cement with four conventional glass-ionomer cement Part 2: Maturation in relation to surface hardness. J Dent. 1999;27:359-65.

19- Lohbauer U. Dental glass ionomer cements as permanent filling material? Properties, limitations and future trends. Materials. 2010;3:76-96.

20- Lucas ME, Arita K, Nishino M. Toughness, bonding and fluoriderelease properties of hydroxyapatite-added glass ionomer cement. Biomaterials. 2003;24:3787-94.

21- Magni E, Ferrari M, Hickel R, Ilie N. Evaluation of the mechanical properties of dental adhesives and glass-ionomer cements. Clin Oral Invest. 2010;14:79-87.

22- Moshaverinia A, Ansari S, Moshaverinia M, Roohpour N, Darr JA, Rehman I. Effect of incorporation of hidroxyapatite and fluoroapatite nanobioceramics into conventional glass ionomer cements (GIC). Acta Biomater. 2008;4:432-40.

23- Pereira LC, Nunes MC, Dibb RG, Powers JM, Roulet JF, Navarro MF. Mechanical properties and bond strength of glass-ionomer cements. J Adhes Dent. 2002;4:73-80.

24- Peutzfeldt A. Restorative materials for the direct technique. In: Roulet JF, DeGrange M. Adhesion: the silent revolution in dentistry. Chicago: Quintessence Publishing; 2000. p. 61-80.

25- Souza-Zaroni WC, Nhani VT, Ciccone-Nogueira JC, Chinalatti MA, Palma-Dibb RG, Corona SA. Shear bond strength of glass-ionomer cements to air-abraded dentin. J Adhes Dent. 2006;8:233-7.

26- Tjandrawinata R, Irie M, Susuki K. Effect of $10 w t \%$ spherical silica filler addition on the various properties of conventional and resin-modified glass-ionomer cements. Acta Odntol Scand. 2005;63:371-5.

27- Wang H, Tang B, Li X, Ma Y. Antibacterial properties and corrosion resistance of nitrogen-doped $\mathrm{TiO}^{2}$ coatings on stainless steel. J Mat Sci Technol. 2011;27:309-16.

28- Wang L, D'Alpino PH, Lopes LG, Pereira JC. Mechanical properties of dental restorative material: relative contribution of laboratory test. J Appl Oral Sci. 2003;11:162-7.

29- Williams JA, Billington RW. Increase in compressive strength of glass ionomer restorative materials with respect to time: a guide to their suitability for use in posterior primary dentition. J Oral Rehab. 1989;16:475-9.

30- Xia Y, Zhang F, Xie H, Gu N. Nanoparticle-reinforced resinbased dental composites. J Dent. 2008;36:450-5.

31- Xie D, Brantley WA, Culbertson BM, Wang G. Mechanical properties and microstructures of glass-ionomer cements. Dent Mater. 2000;16:129-38. 